\title{
O CONCEITO DE TEMPORALIDADE E SUA APLICAÇÃO NA HISTORIOGRAFIA ANTIGA
}

\author{
Juliana Bastos Marques \\ Pós-doutoranda-FFLCH/USP e bolsista da Fapesp
}

\section{Resumo}

Este artigo discute, em um primeiro momento, o conceito de temporalidade e de suas definições e aplicações, bem como algumas contradições inerentes a ele. Como objetivo principal, busca atualizar a discussão sobre como entender o uso da temporalidade dentro do contexto da historiografia antiga, fazendo uma crítica às associações da historiografia greco-romana com a idéia de ciclo e de seu contraponto na historiografia judaico-cristã com a lineari dade. Por fim, sugerimos que é possível ler essas duas diferentes formas de historiografia invertendo seus conceitos comuns de temporalidade, demonstrando assim que tal paradoxo nada mais é do que reflexo dos paradoxos gerais do conceito teórico de temporalidade.

\section{Pallavras-chaves}

Historiografia antiga $\bullet$ tempo $\bullet$ temporalidade $\bullet$ ciclo $\bullet$ decadência.

\section{Abstract}

This article presents, in the first place, a debate on the concepts, definitions and applications of temporality, as well as some of its innate contradictions. The main goal here is to update the discussion about how to understand temporality within the context of Ancient historiography, reviewing the associations of Greek and Roman historiography with the idea of cycle and of its counterpoint, Jewish-Christian historiography, with linearity. Lastly, we suggest that it is possible to read these two different forms of historiography also as an inversion of their associated ideas, thereby demonstrating that this paradox is nothing more than a reflection of the general paradoxes within the concept of temporality itself.

\section{Keywords}

Ancient historiography $\bullet$ time $\bullet$ temporality $\bullet$ cycle $\bullet$ decadence. 
Arnaldo Momigliano foi um dos poucos estudiosos do mundo clássico a refletir sistematicamente sobre o tema da intuição de tempo na historiografia antiga. ${ }^{1}$ Estudos prévios geralmente se centraram na dicotomia específica entre o que a tradição clássica definiu como períodos áureos e outros de decadência em relação a eles. Isso se deu até meados ou mesmo fim do século XX no campo da literatura, através da definição dos cânones estilísticos em grego e em latim, e, no campo da história, pelo debate tradicional e em processo de superação de mecanismos de sucessão das "civilizações" antigas, tanto em termos políticos como sócio-culturais. ${ }^{2}$ No plano do debate teórico propriamente dito sobre tempo, com pontos de contato fortemente presentes com a filosofia e a antropologia, consolidou-se uma oposição entre conceitos pagão e judaico-cristão de tempo, os quais apresentariam um caráter cíclico ou linear, respectivamente. ${ }^{3}$

O propósito deste artigo é rever tais concepções consolidadas de tempo na historiografia antiga, no sentido de apontar como suas dicotomias na verdade se encontram e apresentam relações muito mais complexas do que a princípio se apresentam. A oposição entre tempo cíclico pagão e tempo linear judaicocristão, bem como entre conceitos de auge e decadência no mundo antigo, não é totalmente rígida, e pretendemos demonstrar que, ao desenvolver cada um destes conceitos, encontramos pontos em comum exatamente com os outros aos quais se opõem. Ao considerarmos o debate teórico e metafísico sobre a noção de tempo, encontramos exatamente esse mesmo paradoxo e assim podemos entender melhor os motivos pelos quais as dicotomias acima não são na verdade tão rigorosas. Por fim, o uso do termo "temporalidade" nesta reflexão surge como mais completo do que apenas o mais genérico "tempo", pois per-

\footnotetext{
${ }^{1} \mathrm{O}$ tema aparece constantemente na série de palestras compilada em The classical foundations of modern historiography. Berkeley/Los Angeles: University of California Press, 1990, que expressa suas idéias principais já no período de maturidade intelectual do historiador.

${ }^{2}$ GUARINELLO, N. L. Uma morfologia da História: as formas da História Antiga. Politeia. V. 3, n. 1. Vitória da Conquista , 2003, p. 41-62.

${ }^{3}$ Também define Mazzarino: "Una buona parte dell'indagine moderna - soprattutto della più recente - ha parlato, sulla base di Agostino, di una temporalità circolare pagana, di contro a una temporalità lineare giudaica e infine cristiana. La temporalità pagana consisterebbe nella dottrina dell'Eterno Ritorno; quella giudaica e cristiana in una linea che nel cristianesimo (ossia, nell'età medioevale e moderna) trova come punto di riferimento la Parousia, esprimendosi nel calcolo degli anni Ante Christum e Post Christum natum. La temporalità giudaica e cristiana darebbe un senso alla storia; nella temporalità pagana, la storia non avrebbe un suo significato, perché tutto eternamente ritorna”. MAZZARINO, Santo. Il pensiero storico classico. Vol. 3. Roma-Bari: Editori Laterza, 1990, p. 350. Analisaremos Santo Agostinho e a idéia de eterno retorno em Mircea Eliade adiante.
} 
mite ao historiador trabalhar também com a relação entre tempo, memória e a formação do relato histórico.

Passemos em primeiro lugar à última das questões elencadas acima, pois se trata da nomenclatura que determina as idéias fundamentais do debate: definir o que queremos dizer com "temporalidade", pois ela é diferente de "tempo". Compreenderemos a seguir suas especificidades na narrativa histórica antiga.

\section{Tempo e temporalidade}

Qualquer definição única que se dê à idéia de tempo é indubitavelmente insuficiente para explicá-lo, pois toda racionalização de sua natureza nos leva sempre a certos problemas insolúveis. Assim, o pensamento humano se obriga a limitá-lo em concepções que nos parecem opostas e, ou as aceita conjuntamente, ou prefere uma em detrimento da outra. Trata-se da dicotomia entre o tempo físico, absoluto, alheio à consciência e à vontade, e o tempo psicológico, relativo à experiência e à percepção do ser humano.

Se o tempo físico independe de nós, pois é o tempo da natureza, ele na verdade sequer precisaria ou mesmo poderia ser por nós percebido. É o presente absoluto da ação, já que não é passado nem futuro. O passado não existe, pois já se foi; o futuro também não existe, pois ainda não acontece. Assim, estes dois conceitos apenas fazem sentido dentro da experiência vivida, dentro da racionalização e consciência do seu decorrer - constituem, portanto, o valor da memória e da projeção, causa e conseqüência do momento presente, medido pelo ser humano -, ou seja, o tempo psicológico. Isso significa, em primeiro lugar, que só o presente é real, mas também que qualquer tempo por nós vivido só tem sentido se comparado com o tempo que ainda não é, ou não mais existe - o que se constitui no processo fundamental da consciência humana e, num plano mais restrito e aqui relevante, da apreensão da história. Este tempo é, em suma, a temporalidade. ${ }^{4}$

\footnotetext{
${ }^{4}$ COMTE-SPONVILLE, André. O ser-tempo. São Paulo: Martins Fontes, 2000, p. 30: “O tempo precisa da alma, não para não ser o que ele é (o tempo presente), mas para ser o que já não é ou ainda não é (a soma de um passado e de um futuro), em outras palavras, para ser o que nós chamamos de tempo: ele necessita da alma, não para ser o tempo real, o tempo do mundo, ou da natureza, mas para ser, e é bastante lógico, o tempo... da alma.”. E assim ele define a temporalidade, na página seguinte: “... a unidade - na consciência, por ela, para ela - do passado, do presente e do futuro".
} 
Podemos exemplificar citando Santo Agostinho (354-430 d.C.), que foi um dos principais autores antigos a refletir diretamente, em suas Confissões, ${ }^{5}$ sobre a natureza do tempo. Ele é referência fundamental para o debate, pois adapta as conclusões metafísicas de Platão ao pensamento cristão e oferece uma reflexão sistemática sobre o tema, inédita até então, analisando as contradições entre presente, passado e futuro. Santo Agostinho trata do tempo que a consciência humana apreende que é, portanto, a temporalidade e não o tempo “em si”, já que este não a determina, por ser apenas possível como um presente absoluto.

Se existem coisas futuras e passadas, quero saber onde elas estão. Se ainda não o posso compreender, sei todavia que em qualquer parte onde estiverem, aí não são futuras nem pretéritas, mas presentes. Pois, se também aí são futuras, ainda já não estão; e, se nesse lugar são pretéritas, já lá não estão. Por conseguinte, em qualquer parte onde estiverem, quaisquer que elas sejam, não podem existir senão no presente. Ainda que se narrem os acontecimentos verídicos já passados, a memória relata, não os próprios acontecimentos que já decorreram, mas sim as palavras concebidas pelas imagens daqueles fatos, os quais, ao passarem pelos sentidos, gravaram no espírito uma espécie de vestígios. Por conseguinte, a minha infância, que já não existe presentemente, existe no passado que já não é. Porém a sua imagem, quando a evoco e se torna objeto de alguma descrição, vejo-a no tempo presente, porque ainda está na minha memória. ${ }^{6}$

Mesmo depois de séculos de debate sobre a natureza do tempo, ${ }^{7}$ ainda a mesma conclusão de que a temporalidade prevalece em importância para a consciência humana sobre o tempo pode ser vista, por exemplo, em Heidegger:

\footnotetext{
${ }^{5}$ Todo o Livro XI é dedicado à questão da definição do tempo e do papel de Deus na Criação. Sobre a análise específica da natureza do tempo, ver especialmente o trecho 10-27.

${ }^{6}$ Confissões, XI, 18: "si enim sunt futura et praeterita, volo scire, ubi sint. quod si nondum valeo, scio tamen, ubicumque sunt, non ibi ea futura esse aut praeterita, sed praesentia. nam si et ibi futura sunt, nondum ibi sunt, si et ibi praeterita sunt, iam non ibi sunt. ubicumque ergo sunt, quaecumque sunt, non sunt nisi praesentia. quamquam praeterita cum vera narrantur, ex memoria proferuntur non res ipsae, quae praeterierunt, sed verba concepta ex imaginibus earum, quae in animo velut vestigia per sensus praetereundo fixerunt. pueritia quippe mea, quae iam non est, in tempore praeterito est, quod iam non est; imaginem vero eius, cum eam recolo et narro, in praesenti tempore intueor, quia est adhuc in memoria mea." Tradução de J. Oliveira Santos, S. J. e A. Ambrósio de Pina, S. J. Santo Agostinho. Coleção Os pensadores. São Paulo: Abril, 1973, p. 246.

${ }^{7}$ Para um resumo, ver POMIAN, Kryzstof. Tempo/temporalidade. In: ROMANO, Ruggiero. (dir.) Enciclopédia Einaudi, vol. 29. Lisboa: Imprensa Nacional, 1993, especialmente p. 36-78.
} 
Tempo é ser-aí. (...) O ser-aí sempre está num modo de seu possível ser temporal. (...) O ser-aí não é o tempo, mas a temporalidade. $\mathrm{O}$ enunciado fundamental: o tempo é temporal, é, por isso, a autêntica determinação-e ele não é uma tautologia, porque o ser da temporalidade significa uma realidade desigual. O ser-aí é o seu passar, é a sua possibilidade no seu antecipar a este passar. Neste antecipar sou eu o tempo automaticamente, tenho tempo. Na medida em que o tempo sempre é meu, existem muitos tempos. $O$ tempo é destituído de sentido; tempo é temporal. ${ }^{8}$

Encontramos as raízes da percepção teórica e abstrata da temporalidade não apenas no plano intelectual, mas, também, a partir da realidade cotidiana, a partir do processo, bastante lento, da quantificação temporal que surge progressivamente a partir do século XIV com a invenção dos primeiros relógios mecânicos e a valorização da contagem do tempo no cotidiano. Sendo assim, poderemos verificar que há um movimento paralelo entre a complexidade crescente desta contagem, que se faz progressivamente através dos séculos pela medição de minutos e segundos com a sofisticação dos aparelhos cronográficos, e a sofisticação do conceito abstrato de tempo, refletido tanto no pensamento filosófico quanto na física.

O estágio atual da reflexão sobre a idéia de tempo, num plano mais amplo, parte basicamente de dois pontos principais, que são a teoria física de Isaac Newton e o uso disseminado da cronometria a partir do século XIV ${ }^{9}$ e da invenção do relógio de pêndulo por Christian Huygens no século XVII. A importância primordial de tais fatos constitui-se pela desvinculação da temporalidade do cunho eminentemente religioso e elementar do cotidiano medieval e também na abstração e quantificação do tempo "absoluto". Este passa, então, a ser o

\footnotetext{
${ }^{8}$ HEIDDEGER, Martin. O conceito de tempo. Tradução de Marco Aurélio Werle. Cadernos de Tradução, n² 2, Departamento de Filosofia - USP, 1997, p. 36-37: “Zeit ist Dasein. (...) Das Dasein ist immer in einer Weise seines möglichen Zeitlichseins. (...) Das Dasein ist nicht die Zeit, sondern die Zeitlichkeit. Die Grundaussage: die Zeit ist zeitlich, ist daher die eigentlichste Bestimmung - und sie ist keine Tautologie, weil das Sein der Zeitlichkeit ungleiche Wirklichkeit bedeutet. Das Dasein ist sein Vorbei, ist seine Möglichkeit im Vorlaufen zu diesem Vorbei. In diesem Vorlaufen bin ich die Zeit eigentlich, habe ich Zeit. Sofern die Zeit je meinige ist, gibt es viele Zeiten. Die Zeit ist sinnlos; Zeit ist zeitlich.”

9 “...o século XIV é a época mais importante da história do tempo da Antigüidade ao início do nosso século. Mas não só por ter assistido ao esboço das transformações da arquitetura do tempo: a sua importância deriva do fato de que começaram então a modificar-se as atitudes face ao tempo, à vida, à morte, ao passado e ao futuro.” POMIAN, K., op. cit., p. 29.
} 
elemento fundamental na construção de uma idéia de ciência independente da experiência humana, tal como hoje a vemos.

Newton concebia apenas uma forma básica de tempo como verdadeira, dividida em um tempo absoluto (matemático) e outro relativo (medição). Este tempo físico seria assim para ele apenas uma quantidade mensurável absoluta, bem como o espaço. ${ }^{10}$ Embora seus conceitos tenham sobrevivido sem abalos no campo da física até o século XX, dentro do debate filosófico não tardou a retomada e defesa da idéia de tempo psicológico, em Leibnitz, Hume e especialmente Kant. ${ }^{11}$

Com o desenvolvimento da ciência no século XVIII, as concepções de tempo em geral foram progressivamente sendo tomadas pelo campo da física, tanto que hoje o diálogo entre Bergson, Husserl, Boltzmann e Prigogine ${ }^{12}$ é não só perfeitamente possível como até mesmo obrigatório. Não se pode mais conceber que o tempo físico absoluto da ciência não seja determinante na concepção e existência em si do universo. É, porém, um tempo que acaba se confundindo com a temporalidade subjetiva, enquanto seja apreendido pelo ser humano.

Einstein demonstrou que, diferentemente da idéia de Newton, o tempo absoluto é também relativo. Sua teoria, de grandes implicações para a metafísica do tempo, é ainda apenas uma das correntes científicas atuais que revolucionaram sua definição. As outras, que veremos muito brevemente, são a física quântica, a termodinâmica e a teoria evolucionária de Darwin.

A Teoria da Evolução foi um marco fundamental no processo de formação da concepção atual de temporalidade. A idéia da origem humana passava até então pelo mito e pela transmissão de determinadas cosmogonias, nas quais o tempo mítico é nebuloso e cronologicamente pouco preciso. E isso é válido não só na Antigüidade pagã, pois a concepção da civilização cristã também foi baseada em uma idéia de tempo mítico. Somente a partir da Teoria da Evolução surge o conceito da origem humana como um longo e lento processo natural, mensurável a partir do método científico.

\footnotetext{
${ }^{10}$ Sir Isaac Newton's mathematical principles (Principia Mathematica 1687). Tradução de A. Moore, University of California Press, 1947, p. 6: "Absolute, true, and mathematical time of itself and from its own nature... flows equably without relation to anything external."

${ }^{11} \mathrm{Na}$ parte sobre tempo da Crítica da razão pura, 1787.

${ }^{12}$ Boltzmann (1844-1906) e Prigogine (1917-2003), físico e químico, respectivamente, dedicados ao desenvolvimento da termodinâmica.
} 
A revolução da física no século XX trouxe mais elementos para a questão. Em primeiro lugar, a Teoria Geral da Relatividade de certa forma destrói a idéia de tempo totalmente absoluto e independente, ainda que, para fins práticos de cálculo, a física newtoniana continue a ter valor para uma escala mediana de espaço. A física quântica surge como oposto de Einstein, na medida em que subverte a ordem e a lógica dos acontecimentos no plano molecular. Mas, principalmente a Segunda Lei da Termodinâmica se mostra como o elemento que restabelece e dá nova forma aos pontos principais do conceito de tempo.

Basicamente, essa lei prevê a liberação de energia, como entropia, em qualquer sistema dentro de um tempo linearmente considerado. A implicação básica disso é que, em primeiro lugar, o tempo é irreversível e que, portanto, sua flecha aponta sempre para o futuro - o que a Relatividade não consegue provar. Em segundo lugar, o que é uma conseqüência teórica, mas apenas conjectural, o tempo possivelmente terá um fim, quando toda a energia do universo for liberada e a entropia atingir seu nível máximo.

$\mathrm{O}$ aumento da entropia prevê que um sistema considerado, seja o universo, um corpo humano ou uma xícara de café, passe da ordem para o caos. O melhor exemplo disso é a teoria do Big Bang. Porém, a Teoria da Evolução diz que o universo progride, racionaliza-se e passa do caos para a ordem. Como podemos evitar a contradição? Provou-se que o caos na verdade tem uma tendência à ordem e que apresenta ciclos temporais, como no caso por exemplo do relógio químico. ${ }^{13}$ Se a flecha do tempo da termodinâmica é irreversível, ela engloba a existência de quaisquer processos cíclicos em toda parte do universo, ${ }^{14}$ ou seja, temos portanto que os dois planos fundamentais do tempo são essencialmente interdependentes. E assim, tanto o tempo da física quanto o psicológico, a temporalidade dos filósofos, se constituem em uma estrutura que é ao mesmo tempo linear e cíclica. ${ }^{15}$

\footnotetext{
${ }^{13}$ COVENEY, P. \& HIGHFIELD, R. The arrow of time. London: Flamingo, 1990, p. 182-184.

${ }^{14}$ Idem, p. 36: “... the Second Law of Thermodynamics not only furnishes an arrow of time but also has within it the seeds of the temporal cycles and patterns which we discern in the world around us... Time's arrow represents progress: each instant is branded with an individual marque. But the metaphor of time's cycle is vitally important in seeking patterns within natural phenomena which are ruled by the same laws."

${ }^{15}$ Como conclui Norbert Elias: "Por si só, a expressão 'tempo da natureza', cotejada com 'tempo social', já dá a impressão de que o primeiro tipo de tempo é 'real', enquanto o segundo se reduziria a uma convenção arbitrária. A dificuldade está em que o 'tempo' em si não entra no esquema conceitual desse dualismo. Tal como outros dados, ele se furta a qualquer classificação como 'natural' ou 'social', 'subjetivo' ou 'objetivo', pois é uma coisa e a outra". ELIAS, Norbert. Sobre o tempo. Rio de Janeiro: Jorge Zahar, 1998, p. 94.
} 
Voltemos à História. Também neste plano é possível encontrar a mesma conseqüência demonstrada acima sobre a natureza do tempo, de que ele se constitui em dois planos opostos, porém entrecruzados. Agora, retomando o uso do termo temporalidade, mais adequado à construção do discurso histórico, veremos como ele se apresenta na Antigüidade e como se dão as inter-relações entre seus diferentes sentidos.

\section{Tempo e História na Antigüidade}

O conceito de temporalidade determina hoje a forma da narrativa e dos processos históricos. A História, como disciplina, apresenta atualmente várias formas de uma Zeitauffassung, intuição do tempo, haja vista o pensamento de autores como Marx, Hegel, Braudel e da hermenêutica do século XX, como é o caso de Paul Ricoeur. ${ }^{16}$ Entretanto, a sistematização e reflexão sobre o papel do tempo é um elemento recente na essência da História.

O tempo, como elemento fundamental da História, é construído e não dado como condição primordial desta. ${ }^{17} \mathrm{O}$ conceito original de $1 \sigma \tau$ opı $\alpha$ (historía) entre os gregos sequer se baseia na reflexão sobre a natureza do tempo. Etimologicamente, o termo significa "pesquisa, informação, relato". Heródoto dá importância à investigação dos fatos que pretende narrar e sua atitude, apresentada pelo verbo historeô, demonstra que sua função primordial é buscar as narrativas dos eventos, relatar o que vê e ouve em suas viagens e pesquisas, e assim preservar os fatos mais memoráveis para transmiti-los à posteridade. ${ }^{18} \mathrm{~A}$ importância do relato tem nesse sentido uma associação muito mais próxima com a etnografia do que com a reflexão filosófica - ainda que privilegie a busca da verdade em oposição ao mito, o que torna desde já a narrativa histórica distinta do texto etnográfico. Aliás, se podemos notar, parte quase que exclusivamente

\footnotetext{
${ }^{16}$ RICOEUR, Paul. Temps et récit. Paris: Éditions du Seuil, 1983. Para análise, ver LEAL, Ivanhoé Albuquerque. História e ação na teoria da narratividade de Paul Ricoeur. Rio de Janeiro: Relume Dumará, 2002.

${ }^{17}$ FORNARA, Charles W. The nature of History in Ancient Greece and Rome. Berkeley/London: University of California Press, 1983, p. 91: “... to the Greeks and Romans, 'history' was not an aspect of time; 'the past' and history were no more intrinsically related than were 'the present' and history. The relation was identical for both 'history', was written both of the present and of the past." ${ }^{18}$ Veja-se o caso de Tucídides: “... if one thing is certain it is that when Thucydides said that he collected and wrote things down, he did not know that this made him a historian. Why not? Because the words 'historian'or 'history'did not yet exist, as technical expressions for what Thucydides was doing”. HORNBLOWER, Simon. Thucydides. Baltimore: Johns Hopkins University Press, 1987, p. 12.
} 
da filosofia o estudo do conceito de tempo na Antigüidade - este é o seu campo próprio de definição. ${ }^{19}$

Podemos buscar a origem da importância da temporalidade no conceito atual de história, diferentemente do encontrado em Heródoto e Tucídides no desenvolvimento da cronologia e da genealogia. ${ }^{20}$ A primeira se preocupou exclusivamente com o estabelecimento de sistemas de contagem e sistematização de períodos e eventos, como no caso da contagem dos anos através do calendário olímpico, elaborada por Timeu (c. 356 - 260 a.C.). ${ }^{21}$ Já a segunda é caracterizada pelo relato da tradição de feitos heróicos, misturando lendas e mitos, da qual a Teogonia de Hesíodo (c. 700 a.C.) é o melhor exemplo. Portanto, podemos praticamente descartar a influência de Homero ${ }^{22}$ e começar a traçar os antecedentes da "temporalidade histórica" que nos interessa com os Trabalhos e os dias e o ciclo das Idades que apresenta. ${ }^{23}$

Este texto de Hesíodo é o primeiro exemplo de narrativa centrada na importância do decorrer do tempo, mesmo que ainda não adquira as características de obra histórica - já que não há compromisso sistemático com o relato "verdadeiro" em oposição ao "mítico". É também um típico representante da associação entre pensamento greco-romano e tempo cíclico opostos ao tempo linear judaico-cristão, sobre a qual falaremos adiante. No texto de Hesíodo (Os Trabalhos e os dias, parágrafos 109 a 201), há uma sucessão de cinco raças ou idades dos homens: a primeira e mais elevada é a Idade de Ouro, na época de Cronos, na qual não existia a velhice. Depois surge a Idade de Prata, quando

\footnotetext{
${ }^{19}$ Como exemplo, veja-se ARISTÓTELES, Física, 4, 14.

${ }^{20}$ Para uma análise e crítica da divisão de sub-gêneros historiográficos feita por Jacoby, ver FORNARA, Charles W., op. cit., e MARINCOLA, John. Genre, convention and innovation in Greco-Roman historiography. In: KRAUS, C. S. (ed.). The limits of historiography - Genre and narrative in Ancient historical texts. Leiden/Boston/Köln: Brill, 1999, p. 281-324.

${ }^{21} \mathrm{O}$ mesmo Timeu que é duramente criticado por Políbio no livro XII de suas Histórias.

22 “... não se acha praticamente em Homero pensamento sistemático acerca das origens do mundo ou dos homens. De maneira geral, o tempo dos poemas homéricos não é tanto um contínuo abstrato e sem qualidades mas antes um fenômeno prenhe de atividade.” LLOYD, G. E. R. O tempo no pensamento grego. In: RICOEUR, Paul (ed.). As culturas e o tempo: estudos reunidos pela Unesco. Petrópolis: Vozes, 1975, p. 139.

${ }^{23}$ Veremos adiante como há pontos de contato entre essa tradição grega e os conceitos judaicocristãos, mas veja-se Pattaro: “... o tempo se acha relacionado, na literatura cristã primitiva, ao tema das idades do mundo. As sutis variantes dessa concepção dizem geralmente respeito à história da salvação, que costuma ser dividida em quatro períodos sucessivos, a saber: a idade da lei natural, a da lei mosaica, a da graça e a da glória." PATTARO, Germano. A concepção cristã do tempo. In: RICOEUR, Paul (ed.). As culturas e o tempo: estudos reunidos pela Unesco. Petrópolis: Vozes, 1975, p. 197-198.
} 
os homens, insolentes perante os deuses, viviam cem anos na infância, mas morriam logo após a adolescência. Segue-se a Idade do Bronze, estritamente associada à guerra, e a Idade dos Heróis, também de caráter belicoso, mas justa e valorosa. ${ }^{24}$ A Idade de Ferro seria a própria época de Hesíodo, em que os homens trabalhavam dia e noite e envelheciam rapidamente. Ainda uma raça futura é prevista, raça esta em que os homens já nascerão de cabelos brancos e não terão vergonha ou respeito. Segundo Martin, ${ }^{25}$ podemos inclusive detectar dois ciclos distintos de apogeu e decadência, sendo o primeiro as idades de Ouro, Prata e Bronze, e o segundo a Idade dos Heróis, decaída na do Ferro e na última que virá. Nota-se claramente o movimento de declínio demonstrado na seqüência dos metais e das raças correspondentes, de um passado glorioso a um presente degenerado. ${ }^{26}$

Dentro da tradição historiográfica grega, os momentos nos quais a reflexão sistemática sobre a temporalidade está presente na narrativa são restritos ou circunstanciais. Podemos sugerir ainda a definição de dois planos de desenvolvimento distintos, dentro dos objetivos de nossa reflexão.

Primeiramente, com Heródoto e Tucídides, temos a sucessão de fatos na narrativa de um evento - específico em Tucídides, múltiplos em Heródoto. Isso na Zeitgeschichte grega ("história contemporânea", como assim definia Felix Jacoby) não representa uma forma extensa de temporalidade, justamente porque o objetivo do texto era centrar-se em causas e efeitos de uma realidade contemporânea - nesse sentido, a história grega é a história do presente. ${ }^{27}$

\footnotetext{
24 "The Age of Heroes is clearly an intrusion into an older sequence based on metals. No doubt the intrusion was at least partly the result of chronological schemes and synchronization: when it was realized that the heroes of Homer, such as Achilles, Agamemnon and Odysseus, would have to be placed in a mere Age of Bronze, a special slot for them was inserted that interrupted the decline”. LUCE, T. J. Greek historians. London: Routledge, 1997, p. 12.

${ }^{25}$ MARTIN, R. H. The golden age and the KUKLOS GENESEwN (Cyclical Theory) in Greek and Latin literature. Greece \& Rome. Vol. 12, n. 35/36, 1943, p. 70. Lloyd, op. cit., não vê seis idades, mas apenas cinco.

${ }^{26}$ Já Finley vê o relato de Hesíodo como totalmente atemporal. FINLEY, Moses. Mito, memória e história. In: Uso e abuso da História. São Paulo: Martins Fontes, 1989, p. 8-10.

27 "The most important sub-genre of all for Jacoby was contemporary history (Zeitgeschichte), the writers of which he defined as 'those authors who without local restriction narrated the general Greek history of their own time or up to their own time. "The distinguishing marks of Zeitgeschichte are: (i) a narrative mainly of the author's own time, irrespective of where it begins; (ii) a viewpoint from the Greek side; and (iii) a panhellenic treatment, i.e., embracing events of all the Greek citystates. (...) After Thucydides, writers of Zeitgeschichte chose either to write up individual wars, or to continue the chronicling of contemporary history now focused not on a particular event but rather on a chosen segment of time, as Xenophon did in the Hellenica and as the many serial
} 
Mesmo quando encontramos por exemplo a Archaeologia no início do relato de Tucídides sobre a Guerra do Peloponeso, tal preocupação com a narrativa de uma temporalidade extensa não corresponde à concepção total de sua obra. Existe, porém, uma explicação bastante coerente para este fato em Tucídides que ele utiliza como argumento: a importância de se estabelecer a verdade sobre os fatos impede o historiador de conseguir testemunhos satisfatórios para períodos muito distantes do passado e, por isso, a Archaeologia é apenas uma pequena parte de seu texto. No caso de Tucídides, o que realmente lhe importa é a presença não do perene dos fatos mas sim do imutável das almas, a physis, como causa última do conflito, stasis. ${ }^{28} \mathrm{O}$ segundo plano, em que encontramos Políbio, seria a intuição de causa e efeito como processo histórico mais longo inerente à estrutura da narrativa. Tal contexto surge com a ampliação do arco temporal em obras históricas a partir do período helenístico - as "histórias universais" do próprio Políbio e, por exemplo, Posidônio e Diodoro Sículo.

A reflexão de caráter teórico sobre temporalidade na Antigüidade está de muitas formas confinada a planos restritos e mesmo a percepção cotidiana do tempo não o toma sempre como um valor metafísico fundamental. A Zeitgeschichte grega de Heródoto e Tucídides se abre para novos modelos de narrativa com o passar do tempo, mas isto não significa que incorpore uma conceituação mais sistemática das estruturas de tempo na história. O surgimento da história universal no período helenístico teve Políbio como melhor representante, ainda que sua idéia de ciclos temporais esteja essencialmente vinculada ao debate filosófico sobre as instituições políticas, que os definem, ${ }^{29}$ e não com o desenvolvimento da historía de Heródoto.

A história romana, porém, teria em si a possibilidade de uma conceituação de temporalidade muito maior do que a grega, pois se trata essencialmente da história do desenvolvimento de uma cidade, Roma. De fato, os historiadores

continuators in Greek history attest. Histories centered on individuals (...) also qualify, provided that they are not limited by a local focus.” MARINCOLA, John., op. cit, p. 287.

${ }^{28}$ Sobre Heródoto, o mesmo problema: "[ele apresentava] a mentality that did not see the world as a sequence of events with causes, but rather saw the permanent in a variety of times, places, and changing circumstances; saw, in a word, a recurrent and meaningful process". HUNTER, V. Past and process in Herodotus and Thucydides. Princeton: Princeton University Press, 1982, p. 177.

${ }^{29}$ MOMIGLIANO, A. Ensayos de historiografía antigua y moderna. México: Fondo de Cultura Económica, 1993, p. 166: Já que “... fuera de los capítulos constitucionales, en el resto de su historia Polibio actua como si no tuviera ninguna visión cíclica de la historia”, (...) "Me gustaría tomar a Polibio como una instancia del hecho de que los filósofos griegos solían pensar en términos de ciclos, peo los historiadores griegos no." 
romanos expressaram, ainda que às vezes ocasionalmente, uma grande preocupação com o desenvolvimento de Roma: seu início, o presente e uma certa ansiedade quanto à possibilidade de seu fim. Ainda assim, mesmo com tal ênfase, não podemos dizer que os relatos sobre o passado em Tito Lívio, Salústio ou Tácito abstraiam sistematicamente a idéia de temporalidade.

Tomemos que exista, portanto, na Antigüidade greco-romana, uma reflexão sistemática sobre o tempo "físico" apenas no campo da filosofia, e de formas da temporalidade, em certas instâncias pontuais, em historiadores como Políbio. Essas formas são de fato como veremos, cíclicas. Aliás, o fato mesmo desta própria reflexão existir é a razão inicial para que se associe com freqüência tal idéia de temporalidade ao pensamento greco-romano. Porém, isso não significa necessariamente que o conceito cíclico de tempo seja o único presente, ao contrário da linearidade do tempo judaico-cristão. O que ocorre é justamente o desenvolvimento também da reflexão sistemática deste último como um processo único, irreversível e com sentido definido. Ou seja, afirmar que os pagãos concebiam a circularidade não necessariamente os exclui da possibilidade de compreender formas lineares de tempo.

Assim, o debate atual sobre essas duas concepções - cíclica e linear tornou-se uma boa oportunidade para desfazer a rigidez que tem sido formada em torno de suas caracterizações. Obviamente, temos que reconhecer que as associações originais não deixam de ter um sentido, corroboradas por todo o conjunto de reflexões mencionado - Hesíodo e Políbio ainda são fortes exemplos de pensamento cíclico pagão. Entretanto, quanto mais se encontram falhas em tais associações de conceitos, mais isso significa, em última instância, que é impossível fazer uma distinção absoluta entre as duas concepções de tempo. Primeiro, porque a concepção linear nasce da cíclica, como veremos adiante, e segundo, porque não existe nenhuma teorização tão desenvolvida na Antigüidade que não permita uma certa flexibilidade entre os dois conceitos. ${ }^{30}$

\footnotetext{
${ }^{30}$ PRESS, Gerald A. The development of the idea of history in Antiquity. Kingston/Montreal: McGill-Queen's University Press, 1982, p. 21-22: “... the linear-cyclic account seems incorrect, using as it does a definition utterly alien to antiquity. Although there may be, in some transhistorical sense, a logical connection between the idea of time and the idea of history, the ancients, as a matter of historical fact, did not see them as connected (...). While some writers of historical works say that events repeat themselves and some philosophers speculate about cosmic cycles, there are also other views expressed and no one says that history is circular, repetitious, or meaningless."
} 


\section{Linearidade}

O surgimento da idéia de tempo unidirecional, de sentido fixo e único, foi de certa forma possível através da consolidação do monoteísmo judaico, no qual se pressupõe o poder e a vontade de um deus único que, dessa forma, cria não só o universo como também o tempo. Mircea Eliade interpreta o desenvolvimento do conceito de linearidade entre o povo judeu através da importância da Aliança e da questão do sofrimento: ${ }^{31}$ é a forma de punição divina, expressão da "ira" de Yahveh. Segundo Eliade, o sofrimento só pode ser compreendido e suportado na medida em que se sabe o seu propósito, ou seja, é a expressão da vontade divina, e assim dá valor ao movimento da História.

Até este ponto poderíamos ainda fazer um paralelo com o mundo dos deuses greco-romanos, já que a vontade deles, cuja razão pode ou não ser conhecida, determina importantes acontecimentos na vida cotidiana - no mundo greco-romano, também se sofre por conta da vontade dos deuses. Basta citar, por exemplo, a popularidade do culto à deusa Fortuna que representa uma aceitação do conceito da imprevisibilidade da sorte entre os romanos. Entretanto, há diferenças fundamentais. A primeira é a Aliança de Deus com o povo judeu, um evento único na história, que jamais se repetirá. A partir da Aliança, um evento passado determinante nas ações do presente, o pensamento judaico (e posteriormente cristão, com alterações) fixa a singularidade do tempo e da história. Ainda mais, traz um aspecto novo na percepção de temporalidade entre os antigos: aqui existe a espera de uma revelação divina que se fará em um futuro indeterminado. Os profetas desempenham um papel importante nisso, pois ratificam a idéia da vontade onipotente de Deus ao terem suas profecias realizadas, dando assim um sentido absolutamente unidimensional à história do povo escolhido - seu passado, presente e principalmente futuro. Tal conceito é expandido ainda mais pelo Cristianismo, pois Santo Agostinho mesmo diz que a vinda de Cristo prova como a vontade de Deus é única, e que a paixão, o perdão dos pecados e a ressurreição só poderiam ocorrer uma única vez. ${ }^{32}$ A segunda vinda de Cristo e o Juízo Final, por conseguinte, poriam um fim à história.

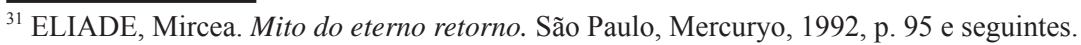

${ }^{32}$ De Civitate Dei, XII, 13: "Semel enim Christus mortuus est pro peccatis nostris; surgens autem a mortuis iam non moritur, et mors ei ultra non dominabitur, et nos post resurrectionem semper cum Domino erimus". "Pois Cristo morreu uma vez pelos nossos pecados e, ressuscitando dos mortos, já não mais pode morrer. Assim como a morte não teve mais domínio sobre ele, nós mesmos depois da ressurreição estaremos com Deus para sempre."
} 
Porém, é falso ver um sentido de progresso definido nessa tal suposta linearidade cristã, em que presumivelmente a humanidade segue se desenvolvendo de forma positiva rumo a uma escatologia redentora. Muito pelo contrário, espera-se um sentido de decadência da humanidade que culmina num defectus finis, em contraposição ao paraíso perfeito do início - uma proposição que vemos desde Daniel até o Apocalipse. Aí está o próprio sentido da redenção.

Por mais paradoxal que seja, encontramos aqui a contradição principal que poderia, a rigor, demonstrar que o tempo linear propriamente dito na verdade não existe, como concepção histórica cristã: se a história tem um começo, a redenção pressupõe o seu fim, e não só o tempo é limitado como ele retoma, no Juízo Final, um estado perfeito inicial. A eternidade não é a princípio histórica, mas sim parte da natureza de Deus e, portanto, não pode ser usada para definir uma linearidade per se. ${ }^{33}$ Assim, o tempo linear cristão seria apenas o tempo "cíclico" de um só ciclo, ${ }^{34}$ pois não se repete.

Mazzarino fornece ainda dois argumentos para corroborar a idéia de que a linearidade judaico-cristã contém elementos da intuição pagã de temporalidade. Em primeiro lugar, o uso da contagem linear do tempo a partir dos anos, antes e depois de Cristo, o que seria a princípio um uso eminentemente linear, que se consolidou até hoje, tem antecedentes na cronografia grega. Poderíamos ir além de Mazzarino e lembrar que as datações judaica e islâmica também utilizam o mecanismo do tempo contado em relação ao antes e depois de um evento, mas também, por exemplo, o mesmo ocorre com todo o cálculo romano utilizado nos anais, relacionados ao tempo decorrido com a fundação de Roma. Afinal, não há uma diferença fundamental de intuição da temporalidade entre esses dois mundos, "la diferenza consiste, piuttosto, nella diversità dei fatti che si pongono a base dell'èra". ${ }^{35}$ No Novo Testamento encontramos um conceito indubitavelmente cíclico. ${ }^{36}$ A Segunda Epístola de são Pedro, ao tratar da espera pelo Juízo Final, traz claramente a idéia de um tempo que é substituído por outro, onde as estruturas do mundo ainda existem, ainda que renovadas: "O que

\footnotetext{
${ }^{33}$ De novo santo Agostinho, Confessiones XI.

${ }^{34}$ Dentro de duas eternidades atemporais. ELIADE, Mircea,. op. cit., p. 101: “... tempo finito, um fragmento (embora também seja cíclico) entre duas eternidades atemporais." Cf. PATTARO, Germano. op. cit., p. 199: “... a realização escatológica arrasta o passado em direção a um futuro cujo ponto de chegada, o dia do Apocalipse, será o ponto culminante de toda a história acabada." - ainda que Pattaro não admita a mesma visão de Eliade.

${ }^{35}$ MAZZARINO, Santo, op. cit., vol. 3, p. 354.

${ }^{36}$ Ibid., p. 419.
} 
nós esperamos, conforme a sua promessa, são novos céus e nova terra, onde habitará a justiça". ${ }^{37}$ É claro que não se trata de um céu e uma terra idênticos aos do mundo atual, mas há ainda uma idéia de caráter circular. Tudo isso significa que o pensamento judaico-cristão ainda dependeu de conceitos e referências temporais também encontrados no mundo greco-romano.

\section{Ciclo}

A importância do esquema cíclico para se compreender a história deriva de uma reflexão paradoxalmente não-característica do pensamento histórico. $\mathrm{O}$ ciclo, e aqui retomamos os conceitos de Mircea Eliade, seria uma resposta à indeterminação da história, uma forma de se contornar o medo das conseqüências imprevisíveis das atitudes no presente, da instabilidade e da mudança em direção ao desconhecido. Seria também, dessa forma, a negação do fim do universo. Afinal o que é um ciclo, senão períodos dentro da existência do universo ou da humanidade que surgem, se desenvolvem e degeneram a um ponto tal que a superação de sua crise implica em outro ciclo idêntico ou semelhante, portanto até certo ponto previsível?

Porém, uma distinção entre categorias cíclicas relativas ao "universo" e à "humanidade" é importante: trata-se de considerar respectivamente um tipo de ciclo cosmogônico em que cada um de seus períodos é exatamente idêntico aos outros, e outro histórico, em que a repetição de algumas estruturas, sejam políticas ou de outra forma institucionais, prevê necessariamente algum tipo de sucessão no desenvolvimento de uma determinada sociedade, o que, em última instância, também acaba revelando um sentido de linearidade - uma "sucessão linear" de ciclos.

O primeiro tipo, o ciclo do universo, é exemplificado pela concepção temporal dos estóicos, baseada na visão pitagórica do universo. Sua idéia de coincidência absoluta dos ciclos está relacionada com a teoria matemática da perfeição do círculo, da imutabilidade ideal e harmoniosa presente no mundo. A mudança para os estóicos é, nesse sentido, desestabilizadora, e mesmo que exista alguma noção de progresso dentro de cada ciclo, nada do que nele resulta é essencialmente válido, pois jamais destruirá a igualdade predeterminada dos

\footnotetext{
${ }^{37} 2$ Pedro, 3:13, "novus vero caelos et terram novam secundum promissum ipsius expectamus, in quibus iustitia habitat.”. Vulgata.
} 
períodos $^{38}$ - a mudança é inerente a uma permanência que sempre se repete. Nesse sentido, a decadência e o fim não são necessariamente uma visão pessimista do mundo, já que a isso se segue um novo, e idêntico, ciclo. Sêneca é um dos autores que tratam dessa questão e, particularmente, é um dos poucos antigos a considerar a possibilidade do progresso para a humanidade. Apenas, nada do que fosse resultado desse progresso teria realmente um valor definitivo de mudança para a melhoria do mundo:

Tudo o que a longa indulgência da fortuna cultivou, tudo o que foi destacado acima do resto das coisas, tudo o que é nobre e belo, mesmo os reinos das grandes nações, tudo será levado à ruína um dia. ${ }^{39}$

O segundo tipo de tempo cíclico é aquele diretamente vinculado à história. A idéia pode ocorrer como o ciclo das instituições políticas de Políbio, ou dentro da existência de um determinado império, cidade ou influência de alguma cidade-estado - ou seja, sempre em torno da ação do poder. ${ }^{40} \mathrm{Na}$ verdade, pelo fato deste tipo não pressupor uma rigorosa identidade entre seus diferentes períodos, como nos ciclos estóicos, podemos dizer que existiria neste esquema uma espécie de "progresso" em alguma direção qualquer. Não que tal progresso seja necessariamente uma forma de desenvolvimento para melhor em relação ao ciclo anterior, mas há sim uma mudança de estados - um tipo particular de continuum em uma direção determinada, ascendente ou descendente.

\footnotetext{
${ }^{38}$ BURY, John B. The idea of progress - An inquiry into its origin and growth. New York: Dover, 1987, p. 18-19 [sobre a importância da Moira, ou Pronoia - providência - para os estóicos]: "Moira meant a fixed order in the universe; (...) It was this order which kept things in their places, assigned to each its proper sphere and function, and drew a definite line, for instance, between men and gods. Human progress towards perfection - towards an ideal of omniscience, or an ideal of happiness, would have been a breaking down of the bars which divide the human from the divine. Human nature does not alter; it is fixed by Moira."

39 "quicquid tam longa fortunae indulgentia excoluit, quicquid supra ceteros extulit, nobilia pariter atque adornata magnarumque gentium regna pessum dabit”. Naturales quaestiones III, 29, 9, citado e analisado em EDELSTEIN, Ludwig. The idea of progress in classical Antiquity. Baltimore: Johns Hopkins Press, 1965, p. 173.

${ }^{40}$ Outro ciclo possível é o "biológico", como em Floro, que traça uma metáfora da história como a vida de um ser - através de seu nascimento, juventude, apogeu, velhice e morte. Ver RUCH, M. Le thème de la croissance organique dans la pensée historique des Romains, de Caton à Florus. In: Aufstieg und Niedergang der römischen Welt. I.2, 1972, p. 827-841 e HAVAS, László. Élements du biologisme dans la conception historique de Tacite. In: Aufstieg und Niedergang der römischen Welt, II, 33.4, p. 2949-2986.
} 
Políbio considera que existem mudanças no tipo de governo, que seguem obrigatoriamente um certo padrão (monarquia-tirania, aristocracia-oligarquia, democracia-oclocracia), ${ }^{41}$ e são determinadas pelo desenvolvimento das instituições políticas, culminando de forma inevitável em uma decadência dos costumes e da moral. Porém, cada vez que ocorre um desses ciclos, seu desenvolvimento significa que nada será igual ao anterior. $\mathrm{O}$ caso mais importante que ele utiliza, de Roma durante as Guerras Púnicas, é exemplar: a constituição mista romana surgiu através da coincidência de uma série de fatores por conta do desenvolvimento da organização social da cidade, mas jamais será novamente idêntica à do período em que Políbio vive. Isso é verdade porque há sempre um quadro de fatores externos e internos em uma determinada situação que nunca é idêntico ou imutável. Em última instância, se existe para Políbio algo que jamais muda, é o processo de corrupção do caráter moral individual dentro de uma sociedade. A decadência advém sempre do luxo e da ganância provenientes do máximo desenvolvimento dentro de uma estrutura política determinada - e este sim é um topos na Antigüidade. Porém, como vimos, o problema de Políbio é justamente a falta de sistematização de seu argumento em sua visão geral da história. ${ }^{42}$

\section{Progresso e decadência em Roma}

O conceito de circularidade não pressupõe necessariamente nenhum tipo de progresso contínuo e duradouro. De fato, a noção de que não tenha existido um sentido verdadeiro de progresso no mundo greco-romano é bastante consolidada na historiografia atual. ${ }^{43}$ Há, no entanto, alguns sinais de sua existência na Antigüidade, ainda que sem a importância que o conceito assumiu após o Renascimento. ${ }^{44} \mathrm{O}$ progresso em geral é sentido em períodos de prosperida-

\footnotetext{
${ }^{41}$ Esquema bastante comum dentro do pensamento político grego, especialmente em Aristóteles. Note-se porém que o termo "oclocracia" é inédito até Políbio (cf. Lidell-Scott).

${ }^{42}$ Cf. nota 25, assim como aponta Starn: "If Rome, through the mixed constitution Polybius described, could escape the downward turn of the cycle as he suggested, if the cyclical plan hardly entered his actual historical narrative, then Polybian cyclism may be taken for a theoretical exercise, another case of historians' indiscriminate borrowing, or for fashionable philosophical talk." STARN, Randolph. Meaning levels in the theme of historical decline. History and theory. Vol. 14, n. 1, 1975, p. 19.

${ }^{43}$ Para um resumo dessa visão, ver BURY, John B., op. cit. Uma abordagem contrastante está em EDELSTEIN, Ludwig. op. cit.

${ }^{44}$ LE GOFF, Jacques. Passado/presente. In: ROMANO, R. (dir.) Enciclopedia Einaudi - memória/ história. Vol. 1. Lisboa: Imprensa Nacional, 1993, p. 301: “... na Antigüidade pagã predominava a valorização do passado, paralelamente à idéia de um presente decadente; (...) na Idade Média, o
} 
de, paz e desenvolvimento, mas toma forma especialmente entre os filósofos antigos em relação ao desenvolvimento técnico-científico - o que é próprio especialmente do período helenístico. O progresso é também uma forma de expressão do poder e, na sua relação com a idéia de decadência, é definido por interesses de determinados grupos na sua promoção. Exemplos adequados para isso podem ser encontrados com grande freqüência e facilidade na história contemporânea, mas uma forma típica no mundo antigo era a propaganda política, literária e religiosa em torno de Augusto, com o surgimento de uma "Idade de Ouro" romana.

$\mathrm{Na}$ verdade, não seria realmente adequado tratar o período de Augusto, visto como "progresso" pelos romanos, em relação a uma República decadente. O contraponto fundamental do conceito antigo de decadência, e romano em particular, é na realidade a idéia de renovação, um tempo virtuoso que retoma o passado exemplar, depois do ponto máximo de um período de declínio. ${ }^{45} \mathrm{~A}$ decadência não necessariamente significa uma postura pessimista e sem esperança, mas sim traz um clima otimista para aqueles que percebem estes sinais: ela prenuncia o advento de um novo período, necessariamente reabilitador. Nesse sentido, a concepção romana de tempo pode sem dúvida ser interpretada como cíclica, ${ }^{46}$ como vemos no surgimento da nova era prenunciada pela Quarta Écloga de Virgílio:

Já chega a última idade cantada pela Sibila de Cumas, e começa de novo o grande ciclo dos séculos.

Já retorna a Justiça, e os tempos em que reina Saturno,

\footnotetext{
presente está encerrado entre o peso do passado e a esperança de um futuro escatológico; (...) no Renascimento, o investimento é feito no presente e (...), do século XVII ao XIX, a ideologia do progresso volta para o futuro a valorização do tempo". Para um histórico da questão a partir do século XIX, ver HERMAN, A. The idea of decline in western History. New York: Free Press, 1997. ${ }^{45}$ Para o papel de Augusto nessa renovação e os paralelos construídos com o passado, veja-se a discussão apresentada em MARQUES, Juliana Bastos. Rômulo, Camilo, Augusto: a Roma renovada de Tito Lívio. In: LESSA, Fábio de Souza; BUSTAMANTE, Regina Maria da Cunha. (orgs.). Memória e festa. Rio de Janeiro: Mauad, 2004, p. 427-434.

46 " $\mathrm{Na}$ Antigüidade, em que o sentimento e a idéia de progresso são praticamente inexistentes, o conceito de decadência não tem verdadeiro contraponto, mas, numa perspectiva religiosa, pode, como acontece em várias épocas do Império Romano, transformar-se, por exemplo, em base e inspiração de um programa político; a idéia de renovatio aparece por vezes como um antídoto de ruína”. LE GOFF, Jacques, Decadência. In: ROMANO, R. (dir.). Enciclopédia Einaudi. Vol. 1. Lisboa: Imprensa Nacional, 1997, p. 394.
} 
já uma nova raça desce do alto dos céus. ${ }^{47}$

O contexto da Quarta Écloga é, no entanto, bastante específico. Ela remete politicamente ao período de paz e expectativa que corresponde à afirmação do poder de Otaviano (ainda em 40 a.C.), mas tem referências que vão desde a astrologia até as antigas tradições dos Oráculos Sibilinos. A seqüência das eras em seus "ciclos" se refere ao conceito de magnus annus que consiste em um período de anos delimitado pela ocorrência sucessiva da mesma disposição de todos os corpos celestes no céu. ${ }^{48}$ Outra leitura considera a tradição etrusca de dez séculos de existência para uma nação, incorporada nos Oráculos Sibilinos. ${ }^{49}$ Seja como for, este é um exemplo da preocupação romana com o correr do seu tempo, com a consolidação de seu passado e a definição de seu futuro. Tais tradições, como também a das águias vistas por Rômulo, ${ }^{50}$ que determinariam um ciclo de doze séculos para o império romano (ou 120 anos, dependendo da interpretação de cada fonte), são absolutamente originais em relação aos gregos e também fundamentais para determinar a grande expectativa dos romanos com o seu destino. E em cada época essa expectativa se caracteriza de forma diferente, de acordo com a realidade vivida: se para Tácito o fim do império certamente virá, ${ }^{51}$ para Virgílio cada fim se configura num novo começo. "Imperium sine fine dedi", diz Júpiter na Eneida $(1,279) .{ }^{52}$

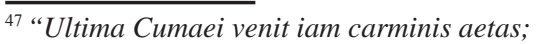
magnus ab integro saeclorum nascitur ordo. iam redit et Virgo, redeunt Saturnia regna, iam nova progenies caelo demittitur alto." Para análise, ver CARCOPINO, Jérome. Virgile et le mystère de la IVe églogue. Paris: L'Artisan du Livre, 1930.

${ }^{48}$ Cf. Cícero, De Republica, VI, 25.

${ }^{49}$ Orac. Sib. 4.47, 8.199. "That the doctrine of saecula was in some form incorporated into the Roman Sibylline tradition is clear from the fact that the dates of the Ludi Saeculares, e.g. in 249 and 149 B.C., were fixed after consultation of the Sibylline Books (Hor. C.S. 5). If the length of a saeculum was officially recognized as 110 years at this time (Hor., ib., 21), then there would have been an expectation that 40/39 B. C. would begin a new age”. COLEMAN, R. (ed.). Vergil, Eclogues (Cambridge Greek and Latin Classics). Cambridge: Cambridge University Press, 1998, p. 131. ${ }^{50}$ Cf. TITO LÍVIO, I, 6-7 e Plutarco, Vida de Rômulo, 9.

${ }^{51}$ Cf. TÁCITO. Germania, 33, com comentário de RIVES, James. Germania. Clarendon Ancient History Series. Oxford: Oxford University Press, 1999, p. 258-260.

52 "E foi só depois da publicação da Eneida que Roma passou a ser chamada de urbs aeterna, com Augusto sendo proclamado o segundo fundador da cidade. (...) Nasceu então a esperança que Roma era capaz de regenerar-se periodicamente, ad infinitum." ELIADE, Mircea., op. cit., p. 116.
} 
Uma das mais significativas características do desenvolvimento da consciência histórica romana é a valorização do passado em relação ao presente, ${ }^{53}$ através da importância do mos maiorum e dos exemplos virtuosos dos antepassados, construídos pela tradição. Ou seja, tal valorização se revela pelo processo de mitificação das origens de Roma, apresentado, por exemplo, em Tito Lívio, e se estende através da consolidação do culto religioso aos antepassados, da importância da memória e do modelo ideal e nostálgico de virtus. Mas, se é verdade que tal ponto é constante dentro do imaginário romano, segue-se logicamente que, por mais que haja um certo movimento de renovação, este nunca é suficientemente bom para substituir de maneira plenamente satisfatória o remoto e perfeitamente virtuoso passado - em particular na questão dos costumes e do caráter moral. Tal conclusão poderia demonstrar agora, dentro de nosso exercício teórico, que a historiografia romana é, na verdade, fundamentalmente linear, pois a renovação, embora remeta à idéia de ciclo, é sempre diferente do passado e pressuporia, assim, uma linearidade intrínseca através de uma sucessão. Vemos assim que é possível demonstrar a validade dos dois aspectos opostos de tempo na história romana, o ciclo e a linha, já que, como afirmamos no início, são afinal de contas conceitos indissolúveis dentro da percepção de temporalidade.

Podemos perceber também a linearidade através de algumas características peculiares do desenvolvimento da cidade e do Império. É importante destacar mais uma vez que a história de Roma é fundamentalmente a história do desenvolvimento de uma cidade, ainda nem que com isso posteriormente sua importância se dilua através da expansão gradativa de outras regiões do Império. É sempre a partir desse foco principal que os historiadores romanos traçam suas abordagens. ${ }^{54}$ Para tanto, e também para todo o imaginário romano, trata-se de considerar as origens, o desenvolvimento e, portanto, a duração de sua existência. Por isso é tão mais importante para o mundo latino a projeção do futuro em comparação com Zeitgeschichte grega. ${ }^{55}$

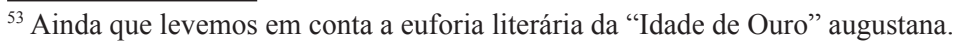

${ }^{54}$ Diferentemente do que fazem os historiadores gregos: "The chief question in the minds of the Latins was one which Greek historiography had never attempted to deal (except incidentally and superficially), for the decline of a city-state or kingdom was sufficiently accounted for in the context of ecumenical history by its defeat in war.” FORNARA, Charles W., op. cit., p. 84.

55 “O pressentimento de um fim 'cientificamente' previsível, da forma como se encontra em Políbio (ou entendido em termos éticos, como em Cícero e Salústio), estabelecia, já na cultura da Roma republicana, uma estreita correlação entre o conceito de decadência e o da previsibilidade
} 
Na verdade, a oposição entre ciclo e linha neste contexto, justamente pela forma como se interconectam, se põe como um falso problema. É possível, como vimos acima, demonstrar os dois lados dentro das características da historiografia romana. Se Tácito menciona a circularidade da história, ${ }^{56}$ certamente há também elementos claramente lineares em seu texto. Sendo assim, Tácito representa de maneira exemplar a questão que colocamos neste artigo - ou seja, a alternância entre circularidade e linearidade como conceitos temporais na historiografia antiga apenas vem a demonstrar um aspecto particular da inter-relação essencial entre esses mesmos conceitos nas outras instâncias de apreensão da temporalidade, inviabilizando em essência uma polarização esquemática. Resumindo, citemos Pomian: "Na prática do historiador (...) nunca se encontram os processos cíclicos, lineares ou estacionários em estado puro. O problema filosófico tradicional - o tempo da história é cíclico, linear ou estacionário? - não tem sentido simplesmente. Porque as três topologias do tempo, que por certo temos o direito de dissociar e opor para as exigências de uma análise lógica, estão na realidade ligadas uma à outra." ${ }^{\text {57 }}$

\section{Referências bibliográficas}

BALDRY, H. C. Who invented the golden age? The classical quarterly. New Series, vol. $2, \mathrm{n}^{\mathrm{o}} 1 / 2,1952$, p. 83-92.

BURY, John B. The idea of progress - an inquiry into its origin and growth. New York: Dover, 1987.

CARCOPINO, Jérome. Virgile et le mystère de la IVe églogue. Paris: L'Artisan du Livre, 1930.

COLEMAN, Robert (ed.). Vergil, Eclogues. Cambridge Greek and Latin Classics. Cambridge: Cambridge University Press, 1998.

COMTE-SPONVILLE, André. O ser-tempo. São Paulo: Martins Fontes, 2000.

EDELSTEIN, Ludwig. The idea of progress in classical Antiquity. Baltimore: Johns Hopkins Press, 1965.

dos fatos históricos." MAZZARINO, Santo. O fim do mundo antigo. São Paulo: Martins Fontes, 1991, p. 29.

${ }^{56}$ Ann. III, 55: "Nisi forte rebus cunctis inest quidam velut orbism ut quem ad modum temporum vices, ita morum vertantur". "A não ser talvez que exista algo como um ciclo em todas as coisas, tanto sazonais quanto morais", analisado em MARQUES, Juliana Bastos. Um ciclo dos costumes em Tácito? Anais III, 55. Boletim do CPA - IFCH/Unicamp, Campinas/SP, 2004, p. 55-65. ${ }^{57}$ POMIAN, K., op. cit., p. 157. 
ELIADE, Mircea. Mito do eterno retorno. São Paulo: Mercuryo, 1992.

ELIAS, Norbert. Sobre o tempo. Rio de Janeiro: Jorge Zahar, 1998.

FINLEY, Moses. Uso e abuso da História. São Paulo: Martins Fontes, 1989.

FORNARA, Charles W. The nature of History in ancient Greece and Rome. Berkeley/London: University of California Press, 1983.

HEIDDEGER, Martin. O conceito de tempo. Tradução de Marco Aurélio Werle. Cadernos de Tradução, nº 2, São Paulo: FFLCH-USP, 1997.

HERMAN, Arthur. The idea of decline in western History. New York: Free Press, 1997.

HORNBLOWER, Simon. Thucydides. Baltimore: Johns Hopkins University Press, 1987.

LE GOFF, Jacques. Passado/presente, in ROMANO, Ruggiero (dir.). Enciclopedia Einaudi - memória/história, vol. 1, Lisboa: Imprensa Nacional, 1993, p. 293-310.

LLOYD, G. E. R. O tempo no pensamento grego. In: RICOEUR, Paul (ed.). As culturas e o tempo: estudos reunidos pela Unesco. Petrópolis: Vozes, 1975, p. 136-149.

LUCE, T. James. Greek historians. London: Routledge, 1997.

MARINCOLA, John. Genre, convention, and innovation in Greco-Roman historiography. In: KRAUS, C. S. (ed). The limits of historiography - genre and narrative in ancient historical texts. Leiden/Boston/Köln: Brill, 1999, p. 281-324.

MARTIN, R. H. The golden age and the KUKLOS GENESEwN (Cyclical theory) in Greek and Latin literature. Greece \& Rome. Vol. 12, no 35/36, 1943, p. 62-71.

MAZZARINO, Santo. Il pensiero storico classico. Roma-Bari: Editori Laterza, 1990.

. O fim do mundo antigo. São Paulo: Martins Fontes, 1991.

MOMIGLIANO, Arnaldo. The classical foundations of modern historiography. Berkeley/Los Angeles: University of California Press, 1990.

. El tiempo en la historiografía antigua. Ensayos de historiografía antigua y moderna. México: Fondo de Cultura Económica, 1993, p. 155-196 (Time in ancient historiography. History and theory. Vol. 6, Beiheft 6: History and the concept of time, 1966, p. 1-23).

PATTARO, Germano. A concepção cristã do tempo. In: RICOEUR, Paul (ed.). As culturas e o tempo: estudos reunidos pela Unesco. Petrópolis: Vozes, 1975, p. 197-228.

POMIAN, Kryzstof. Tempo/temporalidade. In: ROMANO, Ruggiero. (dir.) Enciclopédia Einaudi, vol. 29. Lisboa: Imprensa Nacional, 1993, p. 12-91.

. Ciclo. In: ROMANO, Ruggiero. (dir.) Enciclopédia Einaudi, vol. 29, 
Lisboa: Imprensa Nacional, 1993, p. 103-163.

PRESS, Gerald A. The development of the idea of History in Antiquity. Kingston/ Montreal: McGill-Queen's University Press, 1982.

STARN, Randolph. Meaning levels in the theme of historical decline. History and theory. Vol. 14, n. 1, 1975, p. 1-31.

WHITHROW, Gerald J. Time in History. The evolution of our general awareness of time and temporal perspective. Oxford: Oxford University Press, 1988. 